\title{
Monitoring daily events, coping strategies, and emotion during a desert expedition in the Middle East
}

DOI:

10.1002/smi.2814

\section{Document Version}

Accepted author manuscript

Link to publication record in Manchester Research Explorer

\section{Citation for published version (APA):}

Smith, N., Barrett, E., \& Sandal, G. M. (2018). Monitoring daily events, coping strategies, and emotion during a desert expedition in the Middle East. Stress and Health. https://doi.org/10.1002/smi.2814

\section{Published in:}

Stress and Health

\section{Citing this paper}

Please note that where the full-text provided on Manchester Research Explorer is the Author Accepted Manuscript or Proof version this may differ from the final Published version. If citing, it is advised that you check and use the publisher's definitive version.

\section{General rights}

Copyright and moral rights for the publications made accessible in the Research Explorer are retained by the authors and/or other copyright owners and it is a condition of accessing publications that users recognise and abide by the legal requirements associated with these rights.

\section{Takedown policy}

If you believe that this document breaches copyright please refer to the University of Manchester's Takedown Procedures [http://man.ac.uk/04Y6Bo] or contact uml.scholarlycommunications@manchester.ac.uk providing relevant details, so we can investigate your claim.

\section{OPEN ACCESS}


1 Monitoring daily events, coping strategies and emotion during a desert expedition in the Middle

2 East

\section{Abstract}

Personnel operating in extreme environmental conditions are exposed to a variety of stressors.

Whether a person adjusts to the conditions and is able to cope has implications for their psychological health. In previous extreme environment work, temporal changes in stress, coping and emotion have been reported. Building on previous studies, we used a diary methodology to explore temporal changes in and associations between daily events, coping strategies and affect during a unique hyperarid desert expedition. Four participants undertaking a crossing of the Empty Quarter desert were recruited to the study. Participants completed pre-, post- and 4-month follow-up questionnaires. A

11 daily self-report diary was used to collect situational data. Time-based changes were analysed before testing predictive models linking events and coping strategies with affective responses. Findings suggest that participants had an overall positive experience. There were changes in both the events experienced and coping strategies used during the expedition. Variation in events and coping strategies significantly predicted fluctuations in positive and negative affect. Results offer valuable mechanistic information that could inform monitoring systems aimed at tracking psychological variables during operations in extreme environments. Results are discussed in relation to the novel context, diary methodology, and implications for those operating in extremes.

19 Keywords 


\section{Introduction}

Individuals and groups operating in extreme environmental conditions can be exposed to a variety of stressors. Traditionally, extreme environments were defined as "settings that possess extraordinary physical, psychological, and interpersonal demands that require significant human adaptation for survival and performance" (Manzey \& Lorenz, 1998). There are a variety of professions and activities that require individuals and groups to expose themselves to such extreme conditions; including Antarctic scientists (Palinkas \& Houseal, 2000), submarine operators (Sandal, Endresen, Vaernes, \& Ursin, 1999), astronauts (Kanas et al., 2007), military and defence personnel (Miller, 2006; Vos, Parmak \& Kral, 2012), humanitarian aid workers (Connorton, Perry, Hemenway, \& Miller, 2012), and expeditioners (Atlis, Leon, Sandal, \& Infante, 2004; Leon, Sandal., \& Ciofani, 2011a), amongst others. Despite the longstanding history of studying people in extreme locale, there remains a relative dearth of information regarding the situational experience and individualfunctioning of people in these challenging settings, as well as the specific methods used to counteract and manage stress (Smith, Kinnafick \& Saunders, 2017). This is surprising, especially given the acknowledgement that what happens at the situational level is likely to be a more proximal determinant of psychological health than more distal pre-screening or baseline assessments of individual differences, such as personality (Palinkas \& Suedfeld, 2008).

Within the present study, we aimed to address a number of limitations associated with previous extreme environment work by monitoring the day-to-day experience of a small interdependent expedition group. Specifically, we examined the events experienced, coping strategies used, and emotional response of individuals completing a crossing of the Empty Quarter desert. In contrast to previous studies focused on the Polar Regions (Leon, Sandal \& Larsen, 2011b), the present research centred on a team completing a physical and scientific expedition in the Middle East, starting in Salalah (Oman) and finishing in Doha (Qatar). Specific to this expedition, we anticipated that key situational stressors would include interpersonal demands associated with being with the same group for a prolonged period of time, challenges related to travelling through a monotonous environment, extreme fluctuations in temperature, the role split between the lead and support group, and potential 
issues due to maintaining equipment in the desert environment. As we were interested in examining the temporal changes during the expedition, the transition in and out of the expedition period was also pertinent to the current work. To our knowledge, this is the first psychological study on a group operating in a hyper-arid desert environment. We believe findings will contribute to theoretical and applied understanding of how to maintain psychological health throughout endeavours in similarly demanding environmental conditions.

\section{Psychological functioning in extreme environments}

A commonly studied indicator of health in extreme settings is an individual's affect, which represents their emotions, feelings and mood. In previous expedition studies, weekly and monthly reports of positive affect were found to be rated as considerably higher than corresponding reports of negative affect (Leon et al., 2011b). This finding is consistent with a salutogenic reaction (Antonovsky, 1979) suggesting that for some individuals, stressful environmental conditions may be promotive of health and manifest in positive psychological responses including a sense of enjoyment, satisfaction, and perceptions of personal growth (Palinkas \& Suedfeld, 2008; Suedfeld, 2001). Although positive expedition accounts tend to be more frequently endorsed (Wood, Hysong, Lugg, \& Harm, 2000), and take precedence over more negative experiences (Kjaergaard, Leon, \& Fink., 2015; Leon et al., 2011a), a diverse range of negative emotions, and associated events, have been linked to reductions in team cohesion, well-being, and performance in extremes and therefore remain worthy of investigation (Wagstaff \& Weston, 2014). Additionally, a body of evidence suggests there are likely to be time-based changes in psychological functioning when individuals are exposed to extreme settings (Nicolas, Sandal, Weiss, \& Yusupova, 2013; Sandal, Leon, \& Palinkas., 2006).

Whilst remaining a controversial issue, findings from several extreme environment studies support the existence of a third-quarter effect. The third-quarter model posits that emotional and psychological difficulties should be expected beyond the midpoint and into the third phase of an expedition (Bechtel \& Berning, 1991). For example, a study on Antarctic over-winterers demonstrated increased work-related and interpersonal stress during the third quarter of their 
expedition endeavours (Sandal, 2000). Similar findings were observed by Kahn and Leon (2000) who noted an increase in physical and interpersonal stress towards the mid and latter-parts of a 67-day Antarctic expedition. Additional studies on groups operating in analogous environments have highlighted the potential for irritability, tension and reduction in mood, well-being, and motivation to occur during later phases of the mission (e.g., Steel, 2001; Sandal, Bye, \& van de Vijver, 2011). Together, these findings point towards a reduction in stress-resilience and increased likelihood of difficulties occurring during mid-to-latter stages of expedition activities. Whilst findings from prior research suggest that groups operating in extreme settings may be vulnerable to psychological disruption, certain studies offer a contrasting view and negate the suggestion of a decline in functioning in challenging environments (c.f. Ritsher, Kanas, Ihle, \& Saylor, 2007). Given the equivocal nature of the findings to date, further research is needed to elucidate when challenging events may occur, and the subsequent changes (in the present case, changes in affect) that individuals experience when completing activities in extreme environments. In order to better represent patterns of functioning, and understand the situational experience, assessments should be secured at more regular intervals (i.e., daily as opposed to weekly or monthly). Ultimately, findings from this more intensive sampling process could inform the precise allocation of resources (e.g., when support from ground/mission control is needed) and how to effectively prepare people for changes that might occur prior to them entering extreme settings.

\section{Coping strategies in extreme environments}

The extent to which a person retains a sense of control and reports a positive experience in extreme environmental situations is linked to their ability to cope (Sandal et al., 2006). Coping has been defined in a variety of ways, but essentially refers to the capacity for a person to withstand and counteract physiological and psychological stress (Suedfeld, Brcic, \& Legkaia, 2009). In the current study, we focus on the specific approaches individuals use to manage stress also known as coping strategies. Our conceptualisations are based on broad problem- and emotion-focused coping techniques, consistent with the definitions put forth by Lazarus and Folkman (1984). Problem-focused coping efforts (e.g., problem-solving) are aimed at managing the environment in order to minimize 
the impact of stress. Emotion-oriented approaches aim to make the environment more tolerable by managing one's emotional reaction to it, perhaps by using distraction or reframing the situation.

Past research on the coping strategies used by personnel in extreme settings has included studying polar expedition teams (Leon et al., 2011b), submarine personnel (Sandal et al., 1999), astronauts (Suedfeld et al., 2009), and military recruits (Sandal et al., 1998; Vickers, Ross, Kolar \& Hervig, 1989), amongst others. In prior studies, researchers have found that individuals report a tendency to use a combination of emotion-focused and problem-focused techniques, with few depressive reactions and avoidance methods (Atlis et al., 2004; Leon et al., 2011a). Two broad patterns of findings have been reported in relation to coping strategies in extreme environments. Results from a collection of studies suggest an increase in the use of coping strategies when operating under extreme conditions, indicating that more resources have been activated to deal with the situation (Kahn \& Leon, 2000; Sandal et al., 1998). In contrast, other researchers have reported a decrease in coping strategy use that corresponds with a reduction in mood and could be representative of an apathetic state (Sandal, van der Vijver, Smith, \& Pallesen, 2016). At present, changes in coping strategy use and the clustering of coping approaches in extreme settings remains poorly understood. Moreover, although coping strategies have often been assessed during extreme environment activities, assessments have tended to reflect weekly or monthly timeframes. As such, we still have relatively limited information on the daily methods that individuals use to regulate their experience.

Only a handful of extreme environment studies have directly examined how coping strategies impact upon other indicators of the psychological experience at the situational level (c.f., Kahn \& Leon, 2000; Nicolas et al., 2013; Wagstaff \& Weston, 2014). The lack of research on the day-to-day experience of individuals functioning in challenging environments may be in part due to limitations in current measurement approaches and particularly the reliance on overly burdensome self-report questionnaires. Developing systems that allow us to validly and reliably monitor the psychological experience of individuals and groups operating in challenging environments (such as those in the polar regions, on military deployments, and in space) is critical if we are to effectively track, support, and maintain crew performance and health. In order for monitoring systems to be effective, they must 
be sensitive to changes in the psychological experience, explain variability in outcome measures, and not be overly burdensome for individuals to complete. In the present work, we build on the efforts of other researchers (Kjaergaard et al., 2013; Leon et al., 2011a; Wagstaff \& Weston, 2014) to test a brief and easy-to-complete daily diary that allows individuals to capture key daily events, coping strategy use, and their affective experience whilst living and working in an extreme setting.

\section{The present study}

The first aim of the study was to examine the personal characteristics of the expedition team members, including typical approaches used to manage stress. Scores from baseline were contrasted with 1-month and 4-month follow-up assessments. It was anticipated that expedition team members would report a tendency to use problem-focused and emotion-focused strategies and utilise less depressive or avoidance approaches. Secondly, we used a short daily diary to examine temporal changes in the events experienced, coping strategies used, and affective responses of team members participating in this unique desert expedition. The daily diary included items that reflected coping strategies and affective states examined in the pre-expedition and follow-up surveys. However, this was condensed to a short form that was quick to complete. We did not hypothesise a specific pattern of temporal changes, however were interested in the expedition entry and exit periods (weeks 1 and 7) and the mid-point (weeks 3 and 4) of the crossing. Thirdly, we tested the predictive utility of the daily diary by assessing the relationship between daily events and coping strategies with positive and negative affect.

\section{Method}

\section{Expedition context}

Four male participants were recruited to the present study (ages $=67$ years; 26 years; 54 years; 32 years). Two of the team members came from the United Kingdom, one from Oman, and one from New Zealand. The expedition team departed from Oman (Salalah) on the $10^{\text {th }}$ of December and arrived in Qatar (Doha) on the $26^{\text {th }}$ of January 2016 (48 days) covering over $1300 \mathrm{~km}$ and in the process crossing the Empty Quarter desert, the largest sand desert in the world. There were scientific, 
physical and educational aims for the expedition. During the crossing, the group photographed and collected archaeological artefacts as part of a project on the history of Arabia. Physically, the team were attempting to retrace the first documented crossing of the Empty Quarter completed by Bertram Thomas in 1930. Finally, the crew also uploaded regular blog posts and interacted with the public via social media in order to educate and inspire people about the Empty Quarter and desert landscape.

During the expedition, two of the team completed the challenge on foot with the support of camels, which were used to carry their water and supplies. The team who were on foot, aimed to retrace the steps taken by British explorer Bertram Thomas and relied on historic text and maps to plan their route. One of the on-foot team was very experienced and had completed over twenty expeditions in extreme settings, including operating in polar, desert and mountain environments. The other team member was relatively less experienced and had completed only one prior expedition in a desert context. The support crew followed in $4 x 4$ vehicles and were responsible for ensuring the safety of the on-foot team members, as well as coordinating social media activities and photography. Both support crew were experienced in operating in a variety of extreme and unusual environments, understood how to navigate vehicles through desert terrain, and had completed numerous expeditions in the past ${ }^{1}$. At the end of each day on the expedition, the team camped together and prepared for the following day's march. Although reserve water was carried in the vehicle, this was supplemented by natural wells in the desert and this partly dictated the route. During the expedition, the temperatures changed considerably and ranged from 9 degrees Celsius in the evening to 35 degrees Celsius in the daytime. The team had an on-call remote medical team who could provide support via telepresence in the case on an emergency. Towards the middle of the journey, the team were several hundred kilometres from the nearest medical facility and in the event of a medical situation evacuation would have been particularly challenging.

\section{Procedure}

\footnotetext{
${ }^{1}$ We have purposely not reported specific differences between the expedition subgroups and not provided identifier codes in order to maintain anonymity for the participants.
} 
After receiving ethical approval from the university of the lead author, participants were sent information of the study and asked to sign a consent form. Following informed consent, participants completed a pre-expedition questionnaire. Whilst on the expedition, a daily-rating form (a short, structured diary questionnaire) was completed by the team members at the end of each day. Upon completion of the expedition, the participants completed a follow-up questionnaire at 1-month and 4months after finishing the journey. The first language of one of the team-members was Arabic. As such, all of the measures were translated into Gulf Arabic using standardised back-translation procedures. Although completing the pre-expedition survey in Arabic, the individual team-member completed the remaining survey materials (diary and follow-up) in English.

\section{Measures}

Coping. The Utrecht Coping List (UCL; Schreurs, Tellegen, Van der Willige \& Brosshot, 1988) was used to assess typical ways of coping with problems. The UCL is a 47-item measure which consists of 7 subscales tapping into different types of coping strategy. There are 7 items focused on Active Problem-Solving (e.g., Making a direct intervention when problems occur), 8 items on Palliative Reactions (e.g., Trying to relax), 8 items on Avoidance (e.g., Giving-in in order to avoid difficult situations), 6 on Seeking Social Support (e.g., Sharing one's worries with someone), 7 related to Depressive Reaction Patterns (e.g., Isolating oneself totally from other people), 3 linked to Disclosure of Emotions (e.g., Showing one's annoyance) and 5 associated with Comforting Cognitions (e.g., Telling oneself that things could be worth). When responding to the questionnaire items individuals were asked to think about how they react when confronted with a problem. After reading each item, participants responded using a 4-point Likert scale ranging from 1 (seldom or never) to 4 (very often). There is good evidence for the validity and reliability of the UCL and it has been well-used in previous extreme environment research (Sandal et al. 1999, Leon et al., 2011a).

Positive and negative affect. To examine affect, the Positive and Negative Affect Schedule (PANAS; tapping positive emotions (e.g., interested, enthusiastic) and the other tapping negative emotions (e.g., 
upset, scared). When completing the pre-expedition questionnaire, participants were provided with the stem, "During the past month I have felt..." and asked to respond using a 5-point Likert scale ranging from 1 (very slightly or not at all) to 5 (extremely). During the expedition at the end of each day participants responded to the PANAS using the stem "Today, I have felt..." using the same scale. The PANAS has been demonstrated as a valid and reliable measure of emotions in many studies (Crawford \& Henry, 2004) and has been well used in extreme environment settings (Palinkas \& Suedfeld, 2008).

Depression. The Centre for Epidemiologic Studies Depression Scale-Revised (CESD-R; Eaton et al., 2004) was used to assess mood prior to the expedition. The 20 -item revised CESD-R provides a score for 9 different depression symptom groups (e.g., Concentrating - "I had trouble keeping my mind on what I was doing"; Sadness - "I felt depressed"). The overall CESD-R score is used as a clinical assessment and categorises depression according to varying degrees of severity. When completing the scale, participants responded to the stem "During the past month..." and based their answers on a 4point Likert scale ranging from 1 (Rarely or none of the time - less than 1 day) to 4 (Most or all of the time $-5-7$ days). Scores below 16 indicate no clinical significance. Values above 16 can be interpreted in a variety of ways depending on the combination of scores. The CESD-R has been demonstrated as a valid and reliable measurement instrument (Van Dam \& Earleywine, 2011) and has previously been used to assess those undertaking long stays in extreme environmental conditions (Grant et al., 2007).

Daily ratings form. We used a modified version of the rating form employed by Leon and colleagues in previous expedition projects (Atlis et al., 2004; Leon et al., 2011). The daily rating form was refined and reformatted prior to being used in the present investigation. The form included items related to affect (PANAS discussed above), perceived stress (based on a Borg scale; Borg, 1981), daily events experienced, and coping strategies used (single items that align with subscales included in the UCL). Within the daily rating form, stress was reported using a 10-point scale ranging from 1 (not at all) to 10 (very much so). Events experienced and coping strategies used were designated with 
a yes/no response and coded as 0 (did not happen/did not use) and 1 (did happen/did use). The rating form took approximately 5 minutes to complete each day.

\section{Data analysis}

Given the small number of study participants, we adopted analytical approaches consistent nof-1 clinical trials (Lille et al., 2011). Initially we computed descriptive statistics for all of the assessed variables. Changes in daily events and coping strategies were then examined according to weeks of the expedition. Mixed effects analyses of variance were computed including expedition week as the explanatory variable and the different events and coping strategies as outcomes. A Bonferroni correction was applied for post-hoc testing and more conservative $\mathrm{p}$-value used to interpret findings $(0.05 / 21=0.002)$. For variables where significant weekly time-based changes were identified, these were plotted on a graph and individual differences represented. We also plotted weekly affect scores across the expedition period, including pre-expedition scores and 1-month and 4month post follow-ups.

To address the second aim of the study and examine the link between events, coping strategies, and affect we again tested a series of multi-level models. A two-level fixed effects model was specified where responses (level 1) were nested within participants (level 2). This approach is appropriate when dealing with nested data and has demonstrated reliability with small sample sizes (Bell, Ferron, \& Kromrey, 2008). When running the MLM models, initial empty models were computed in order to partition the variance linked to the nesting of responses within participants (Model 0). Predictor variables (events and coping strategies) were included in Model 1 to explain variability in the respective outcome variable (positive and negative affect).

Prior to the expedition, participants reported a tendency to use active problem-solving approaches $(\mathrm{M}=3.21)$ and comforting cognitions $(\mathrm{M}=2.85)$ when dealing with challenging situations. Depressive reactions tended to be scored low $(\mathrm{M}=1.57)$. All team members reported moderate to high ratings for positive affect $(\mathrm{M}=3.80)$ and generally negative affect was reported to 
be low $(\mathrm{M}=1.10)$. However, one individual (A) did report considerably higher pre-expedition negative affect scores than the other team members. On average, pre-expedition scores for depression were below the clinical threshold of $16(\mathrm{M}=10.50)$, but again the value for participant A was 19 and aligned with their negative affectivity. At 1-month post expedition, there was a reduction in all of the coping strategies assessed in the UCL, followed by a recovery back to pre-expedition levels at the 4month follow up. Positive affect scores were consistent with pre-expedition values when assessed at the 1-month follow-up $(\mathrm{M}=3.80)$ and showed a marked increase at the 4-month assessment $(\mathrm{M}=$ 4.43). Both negative affect and depression scores declined from the pre-expedition into the 1-month and 4-month follow up phases. See Table 1 for further details on pre-expedition values and individual team member values.

-INSERT TABLE 1 HERE

$=104)$. The most frequently reported coping strategy was thinking of something pleasant $(\mathrm{N}=96)$. A full list of the events experienced and coping strategies used is provided in Tables 2 and 3. A number of significant findings emerged when examining temporal differences in the events experienced and coping strategies endorsed during the expedition. Temporal findings related to events are presented in Table 2 and findings related to temporal changes in coping strategies are presented in Table 3. Significant time-based effects are presented in plots in Figures $1(1 \mathrm{a}-1 \mathrm{~d})$ and $2(2 \mathrm{a}-2 \mathrm{c})$.

In Figure 3, temporal scores for positive and negative affect are presented. Overall, scores for positive affect were moderate and values for negative affect remained relatively low. Both positive and negative affect decreased between pre-expedition ratings and week one ratings. A further decrease in positive affect and slight increase in negative affect emerged at week 5 of the expedition, although the changes were not significant. In the follow-up phases negative affect remained low, however positive affect increased beyond pre-expedition scores. 
Findings from MLM analyses linking daily events to positive and negative affect are presented in Table 4. Feelings of satisfaction in making good progress and being able to cope were associated with higher levels of daily positive affect. Muscle and joint pain was associated with lower daily positive affect scores. Problems with gear, fear of injury, concerns about decisions, worries about family, and concerns about team working all predicted higher daily negative affect scores.

Findings related to the MLM model linking coping strategies and daily affect are presented in Table 5. Thinking of something pleasant, seeing the situation in a positive way, and efforts to relax were associated with higher daily positive affect scores. Negative feelings about a teammate and discussing personal concerns were linked to lower positive affect scores. Discussing task concerns,

\section{Discussion} situational experience of the team. Using a diary-study method we assessed day-to-day changes in factors (events \& coping strategies) related to psychological health (i.e., affect). Notably, findings

The overall purpose of the present study was to examine the psychological experience of a group undertaking an expedition in a unique desert context. We were interested in the profile of the expedition group, temporal changes that occur during and post expedition, and understanding the highlighted specific events and coping strategies associated with changes in daily positive and negative affect. To our knowledge this is also the first psychological study published in the context of a hyper-arid desert expedition. Given the novel location, route, and format of the expedition, findings offer valuable insight into understanding the experience of other individuals and groups, such as expeditioners, aid workers and, defence and security personnel operating in comparable settings.

At the pre-expedition phase, participants reported a tendency to use more active-problem 
strategies. These tendencies have previously characterised other individuals and groups operating in extreme settings and are suggestive of a well-adapted group (Kjaergaard et al., 2015; Leon et al., 2011a). During the expedition, daily positive affect remained at a moderate level. Daily negative affect tended to be scored low. Scores for affective states are similar in magnitude to those reported throughout other expedition studies (Leon et al., 2011b). There were no significant temporal changes in positive and negative affect during the expedition, although there was an observable decline in positive affect during week 5 of the expedition. In the 1-month post and 4-month follow-up, there was a trend for positive affect to be elevated compared to pre- and in-expedition levels. Satisfaction can be derived from overcoming the challenges faced on the expedition, which is likely to manifest in positive feelings and emotions as evidence by the elevated positive affect score in the present work (Suedfeld, 2001). Negative affect scores remained low through the post-expedition assessments and depression scores were reduced compared to pre-expedition values. One individual (A) reported depression scores beyond the value of 16 used in clinical screening assessments. On further inspection of his responses, it was evident that this individual had experienced disturbed sleep on the run up to the expedition. Overall, the descriptive accounts from the pre- and follow-up phases generally point towards a group who derived benefits from the expedition and coped well with the transition out of expedition life.

During the expedition, the team frequently reported having a positive experience, consonant with the view that extreme environment activities may be promotive of health (Suedfeld, 2001).

Despite the relatively positive account, a number of significant temporal changes in logged variables were noted. In the present study, observed changes did not fit a distinctive pattern such as the thirdquarter (Bechtel \& Berning, 1991) and were not specific to either of the two sub-teams. During the expedition, there was a significant decrease in concerns about teammate wellbeing. At the individual level, all team members reported a gradual decline in concern for teammate wellbeing throughout the expedition. Team member B did report an increase in concern at week 5, which may coincide with a particular experience at that point in time (see Figures 1a-1d). These types of change may be indicative of individuals becoming less benevolent towards each other, which has been found in 
previous extreme environment research (e.g., Palinkas, 2003; Sandal et al., 1998; Sandal et al., 2011; Wagstaff \& Weston, 2014). Such an interpretation is supported by the descriptive changes and reductions in reports of camaraderie by all team members throughout the expedition.

Remaining changes may reflect the environment becoming normalised. For instance, reductions in satisfaction that equipment is working, worries about friends and family and enjoyment of the environment are likely to indicate a levelling of the psychological experience (Steine, Steine, Sandbaek, \& Roseth, 2003). Upon entering the expedition, some individuals may worry about leaving family behind and be concerned about whether equipment is going to work. After spending a short period of time adjusting and successfully dealing with initial difficulties, reduction in these types of report would be expected. Conversely, after the initial excitement of starting the expedition and being in a new environment, enjoyment of the conditions is likely to wane. This represents the monotony of seeing the same type of environment and landscape for a prolonged period of time.

In terms of coping, the most frequently reported strategies during the expedition reflected emotion-oriented attempts aimed at modifying thoughts and feelings (i.e., comforting cognitions). Although all team members reported a baseline tendency to use active problem-solving strategies, there is a limit to the degree to which individuals are able to change the situation during an expedition. Furthermore, in the absence of particular challenges or when problem-focused strategies fail or are not needed, such strategies are less likely to be utilised. In this circumstance, we may expect emotionoriented approaches, such as reappraisal and managing thoughts to take precedence. Finding from polar environments support this notion and emphasise the value of emotion-focused coping approaches (Kjaergaard et al., 2015; Leon et al., 2011a; Wagstaff \& Weston, 2014). At the 1-month follow-up phase, there was a reduction in all of the coping strategies measured in the UCL, suggestive of a reduction in stress resilience (Sandal et al., 2016). At the 4-month assessment, coping strategy use returned to pre-expedition levels indicative of post-stress recovery.

Several changes in coping strategy use emerged during the expedition. There was an increase in thinking of something pleasant towards the end of the expedition. In the third and final phases of 
the expedition there was also a significant decrease in attempts to see the situation in a positive way, which has previously been observed in the mid-to-latter phases of other extreme endeavours (Steel, 2001). Together these changes in coping strategy indicate a refocusing of attention from the immediate situation to a future-time when the expedition is due to finish. An interesting observation was that discussing task concerns became less utilised by all team members later in the expedition, which coincided with a decrease in reports of camaraderie and reaffirms the interpretation of a less benevolent group (Sandal et al., 2011). It is important to note that there were differences between the expedition team members on the coping strategies used and not all team members displayed the same pattern. Therefore, individual differences in such coping approaches should still be considered (see Figures 2a-2c). In upcoming expedition work, it would be interesting to further explore the interaction between coping strategies and re-examine how a person's time-perspective shifts during the endeavour and the impact this has on coping with the demands of the environment. Outside of extreme settings, time-perspective has been linked to experiences of stress and the use of coping strategies pertinent to the present investigation (Ho \& Yeung, 2016). The focus on time-perspective could be particularly relevant for expeditions or deployments that have a shifting end point, which may require individuals to focus more on the 'here-and-now' as opposed to the anticipated end point.

Links between expedition events and coping strategies were examined in relation to positive and negative affect. Satisfaction in making progress and being able to cope with the challenge were linked to higher daily positive affect scores. These events represent a sense of control, highlight the task effectiveness of the individuals and group, and would be expected to result in positive responses (Palinkas \& Suedfeld, 2008). Muscle and joint pain was linked to lower daily positive affect, emphasising the importance of maintaining physical health whilst operating in demanding environments. A number of events (e.g., gear problems) also predicted elevated levels of daily negative affect. Of particular interest, were the positive associations found between concerns about safety decisions, team-working, and worries about friends and family, with raised negative affect. Such results reinforce the propositions that interpersonal and relational aspects, such as feeling homesick and missing family, are often the biggest source of stress in extreme settings (Sandal et al., 
2006; Stuster, Bachelard, \& Suedfeld, 2000). These types of difficulties may need to be targeted during planning, group training, and information gathering prior to going into extreme environments.

Thinking of something pleasant, seeing the situation in a positive way, and relaxing, were all associated with elevated positive affect scores. These relationships highlight the value of emotionoriented coping approaches when spending long-durations in challenging environments. Having negative feelings about a teammate and discussing personal concerns were related to lower positive affect and higher daily negative affect. When individuals endorse such techniques, it signals difficulties associated with group functioning and if left unmanaged could result in disruption and impaired psychological health. Keeping feelings to oneself was also linked to higher negative affect. Although concealing feelings may help preserve the status quo, over the long term this may be maladaptive for effective functioning especially in highly interdependent groups. Understanding which strategies can be used to maintain or boost positive affect, and mitigate negative affective experiences, will likely help sustain the performance and health of individuals and groups under duress. In a recent article, Leach (2016) suggested that when exposed to exceptional, extreme, and torturous environments small but regular bursts of positive emotion can help sustain psychological health. As such, having an appreciation of the strategies that will allow us to achieve this emotion regulation is important.

There are a number of limitations to acknowledge in relation to the present findings. Data presented are based on a very small number of participants and caution should be taken when generalising beyond this specific group. Sample-size issues pose a consistent challenge when conducting research with extreme environment populations. However, to overcome this challenge, a rigorous diary-study method was employed (Iida, Shrout, Laurencau, \& Bolger, 2012) and repeated measures were collected from the participants that resulted in high fidelity and a robust number of data points. Another limitation is related to the extent to which the expedition was experienced as stressful. On average, daily stress was reported as 2.79 suggesting a relatively low perception of difficulty. Whilst stress was reported as low, the characteristics of the expedition are similar to what might be experienced during other types of endeavour in challenging environments and do warrant 
research attention (e.g., monotony, team difficulties). It is also important to note that data were collected by self-report questionnaire. Whilst more situational assessments were made using the daily rating forms, these reports remain subjective and it is possible that individuals may attempt to mask their true feelings. In future work it may be pertinent to include other more objective forms of data collection (e.g., behavioural observation, physiological monitoring) in order to triangulate the psychological information collected.

\section{Implications for individuals and groups in extreme environments}

In spite of the study limitations, results are promising and have clear practical application to other individuals and groups operating in extremis. There was modest evidence for temporal changes in the psychological experience of the expedition team. However, it remains unclear whether these changes align with a consistent phase-change model or instead represent the environment becoming normalised and the novelty of the experience subdued. Linking such findings to physiological changes e.g., changes in cortisol, would provide a better understanding of phase-changes related to stress.

Results linked to the predictive validity of the diary are particularly encouraging. If further research replicates the associations observed in the current work and suggests that the pattern of coping and emotional responses can be generalised to similar expeditions/deployments in other extreme contexts, it may be beneficial to brief personnel on what to expect during challenging activities, to prepare them for inevitable emotional ups and downs of endeavours in difficult environments. The present research highlighted the importance of monitoring social relationships.

Attending to this in preparation for a mission or expedition (e.g., by discussing how the team will deal with interpersonal tensions as part of training) may enhance individuals' ability to cope when relationships start to become strained.

The method of assessment used to assess events and coping (yes/no response) is simple to use and not overly burdensome on participants, whilst also explaining variability in daily positive and negative affect scores. If such findings are replicated in upcoming work, this could inform development of a digitised system that would allow individuals to monitor events, coping, and 
MONITORING EVENTS, COPING STRATEGIES, AND EMOTION

441 affective responses during assignments in a range of extreme settings. Retrospective analysis of such

442 data could then inform the preparation of future missions. This approach also has the potential to

443 develop into a tool for those supporting or participating in missions to track responses in real (or close

444 to real) time. This could, in turn, inform decision-making about action to address a pattern of negative

445 responses, including whether and when to abort a mission or expedition.

In sum, the current study offers a unique insight into the demands faced by individuals

operating in a challenging hyper-arid desert environment. Addressing a gap in the research literature,

we have identified specific events and coping strategies linked to situational changes in affect during

an expedition in a desert environment. Such findings offer a foundation for developing a valid and

reliable system that can be used by individuals and organisation to track situational-indicators of psychological health in extreme contexts.

\section{References}

Antonovsky A. (1987). Unraveling the mystery of health: How people manage stress and stay well. San Francisco, CA: Jossey-Bass.

Atlis M. M., Leon G. R., Sandal G. M., Infante M. (2004). Decision processes and interactions during a two-woman traverse of Antarctica. Environment and Behavior, 36, 402-423. https://doi.org/10.1177/0013916503262217

Bechtel R. B., \& Berning, A. (1991). The third-quarter phenomenon: do people experience discomfort after stress has passed? In: Harrison AA, Clearwater YA, McKay CP, eds. From Antarctica to outer space: life in isolation and confinement New York: Springer-Verlag, 261-66.

Bell, B.A., Ferron, J.M., \& Kromrey, J.D. (2008). Cluster size in multilevel models: The impact of sparse data structures on point and interval estimates in two-level models. Proceedings of the Joint Statistical Meetings, Survey Research Methods Section.

Borg, G. O. (1982). Psychophysical bases of perceived exertion. Medicine \& Science in Sports \& Exercise, 14, 377-381. 
MONITORING EVENTS, COPING STRATEGIES, AND EMOTION

466

Crawford, J. R., \& Henry, J. D. (2004). The positive and negative affect schedule (PANAS): construct validity, measurement properties and normative data in a large non-clinical sample. British Journal of Clinical Psychology, 43, 245-265. https://doi.org/10.1348/0144665031752934

Eaton W. W, Muntaner C, Smith C, Tien A, Ybarra M. (2004). Center for Epidemiologic Studies Depression Scale: Review and revision (CESD and CESD-R). In: Maruish ME, ed. The Use of Psychological Testing for Treatment Planning and Outcomes Assessment. 3rd ed. Mahwah, NJ: Lawrence Erlbaum; 363-377.

Grant, I., Eriksen, H. R., Marquis, P., Orre, J. J., Palinkas, L. A., Suedfeld, P., Svensen, E., \& Ursin, H. (2007). Psychological selection of Antarctic personnel: The "SOAP" instrument. Aviation, Space, and Environmental Medicine, 78, 793-801.

Ho, H. C. Y., \& Yeung, D. Y. (2016). Effects of occupational future time perspective on managing stressful work situations. International Journal of Psychology, 51, 243-322. https://doi.org/10.1002/ijop.12144

Iida, M., Shrout, P. E., Laurenceau, J-P., \& Bolger, N. (2012). Using diary methods in psychological research. In H. Cooper (Ed.) APA Handbook of Research Methods in Psychology: Vol 1. American Psychological Association.

Kanas, N.A., Salnitskiy, V.P., Boyd, J.E., Gushin, V.I., Weiss, D.S., Saylor, S.A., Kozerenko, O.P., and Marmar, C.R. (2007). Crewmember and mission control personnel interactions during International Space Station missions. Aviation, Space, and Environmental Medicine, 78, 601607.

Kahn, P. M. and Leon, G. R. (2000). Group Climate \& Individual Functioning in an All- women Antarctic Expedition Team. Journal of Human Performance in Extreme Environments, 5, 35-43. DOI: $10.7771 / 2327-2937.1005$

Kjaergaard, A., Leon, G. R., \& Fink, B. A. (2015). Personal Challenges, Communication Processes, and Team Effectiveness in Military Special Patrol Teams Operating in a Polar Environment. Environment \& Behavior, 47, 644-666. https://doi.org/10.1177/0013916513512834

Kjærgaard, A., Venables, N. C., Leon, G. R., \& Fink, B. A. (2013). Personality, personal values and 
MONITORING EVENTS, COPING STRATEGIES, AND EMOTION

growth in military special unit patrol teams operating in a polar environment. Military Psychology, 25, 13-22. doi:10.1037/h0094753

Lazarus, R.S. and Folkman, S. 1984. Stress, Appraisal, and Coping. New York: Springer.

Leach, J. Psychological factors in exceptional, extreme and torturous environments. Extreme Physiology and Medicine, 5, 1-15. DOI: 10.1186/s13728-016-0048-y

Leon, G. R., Sandal, G. M., \& Larsen, E. (2011b). Human performance in polar environments. Journal of Environmental Psychology, 31, 353-360. https://doi.org/10.1016/j.jenvp.2011.08.001

Leon, G. R., Sandal, G. M., Fink, B. A., \& Ciofani, P. (2011a). Positive experiences and personal growth in a two-man North Pole expedition team. Environment \& Behavior, 43, 710-731. https://doi.org/10.1177/0013916510375039

Lille, E. O., Patay, B., Diamant, J., Issell., Topol, E. J., \& Schork, N. J. (2011). The n-of-1 clinical trial: the ultimate strategy for individualising medicine? Personalised Medicine, 8, 161-173. doi: $10.2217 /$ pme. 11.7

Manzey, D., \& Lorenz B. (1998). Mental performance during short-term and longterm spaceflight. Brain Research Reviews, 28, 215-221. https://doi.org/10.1016/S01650173(98)00041-1

Miller, L. Undercover Policing: A Psychological and Operational Guide. Journal of Police and Criminal Psychology, 21, 1-24.

Nicolas, M., Sandal, G. M., Weiss, K., \& Yusupova, A. (2013). Mars-105 Study: Time-courses and relationships between coping, defense mechanisms, emotions and depression. Journal of Environmental Psychology, 35, 52-58. https://doi.org/10.1016/j.jenvp.2013.05.001

Palinkas L. A. (2003). The psychology of isolated and confined environments: understanding human behavior in Antarctica. American Psychologist, 58, 353-63.

Palinkas LA, Houseal M. (2000). Stages of change in mood and behavior during a winter in Antarctica. Environment \& Behavior, 32, 128-41. https://doi.org/10.1177/00139160021972469

Palinkas, L. A., \& Suedfeld, P. (2008). Psychological effects of polar expeditions. Lancet, 371, 153163. DOI: https://doi.org/10.1016/S0140-6736(07)61056-3 
MONITORING EVENTS, COPING STRATEGIES, AND EMOTION

Ritsher, J.B., Kanas, N.A., Ihle, E.C., and Saylor, S.A. 2007. Psychological adaptation and salutogenesis in space: lessons from a series of studies. Acta Astronautica. 60, 336-340. https://doi.org/10.1016/j.actaastro.2006.09.002

Sandal, G. M. (2000). Coping in Antarctica: is it possible to generalize across settings. Aviation, Space, and Environmental Medicine, 71, 37-43.

Sandal, G. M., Bye, H. H., \& van de Vijver, F. J. R. (2011). Personal values and crew compatibility: Results from a 105 days simulated space mission. Acta Astronautrica, 69, 141-149. DOI: 10.1016/j.actaastro.2011.02.007

Sandal, G. M., Leon, G., \& Palinkas, L. (2006). Human challenges in polar and space environments. Environmental Science and Biotechnology, 5, 281-296.

Sandal, G. M., Endresen, I. M., Vaernes, R., \& Ursin, H. (1999). Personality and coping strategies during submarine missions. Military Psychology, 11, 381-404. doi:10.1207/s15327876mp1104_3

Sandal, G. M., van der Vijver., Smith, N., \& Pallesen, S. (2016). Psychological resilience during overwintering in Antarctica. Paper presented at International Astronautical Congress, Guadalajara, Mexico, September, 2016.

Sandal, G. M., Grønningsæter, H., Eriksen, H. E., Gravraakmo, A., Birkeland, K., \& Ursin, H. (1998). Personality and endocrine activation in military situations. Military Psychology, 10, 45-61. ttps://doi.org/10.1207/s15327876mp1001_4

Schreurs, P. J. G., Tellegen, B., Van der Willige, G., \& Brosshot, J. F. (1988). Utrecht Coping List: Handbook. Lisse, Belgium: Swets \& Zeitlinger.

Smith, N., Kinnafick, F., \& Saunders, B. (2017). Coping Strategies Used During an Extreme Antarctic Expedition. Journal of Human Performance in Extreme Environments, 13, 1-10. DOI: $10.7771 / 2327-2937.1078$

Steel, D. G. (2001). Polar Moods: Third Quarter Phenomena in the Antarctic. Environment \& Behavior, 33, 126-133. https://doi.org/10.1177/00139160121972909 
Steine S, Steine K, Sandbaek G, Roseth AG. (2003). A polar expedition in challenging circumstances-experiences and psychological reactions. Tidsskr Nor Laegeforen, 123, 352428.

Stuster J. Bachelard C, Suedfeld P. (2000). The relative importance of behavioral issues during longduration ICE missions. Aviation, Space, and Environmental Medicine, 71, A17-25.

Suedfeld, P. (2001). Applying positive psychology in the study of extreme environments. Journal of Human Performance in Extreme Environments, 6, 21-25. DOI: 10.7771/2327-2937.1020

Suedfeld, P., Brcic, J., \& Legkaia, K. (2009). Coping with the problems of spaceflight: Reports from astronauts and cosmonauts. Acta Astronautica, 65, 312-324. https://doi.org/10.1016/j.actaastro.2009.02.009

Van Dam, N.T. \& Earleywine, M. (2011). Validation of the Center for Epidemiologic Studies Depression Scale - Revised (CESD-R): Pragmatic depression assessment in the general population. Psychiatry Research, 186, 128-132. https://doi.org/10.1016/j.psychres.2010.08.018

Vickers, J., Ross, R., Kolar, D. W., \& Hervig, L. K. (1989). Personality correlates of coping with military basic training. San Diego, CA: Naval Health Research Centre.

Vos, A., Parmak, M., \& Kral, P. (2012). Chapter 1 - Introduction. In Psychological and physiological selection of military special operations forces personnel. North Atlantic Treaty Organisation RTO Technical Report TR-HFM-171.

Wagstaff, C. R. D., \& Weston, N. J. V. (2014). Examining Emotion Regulation in an Isolated Performance Team in Antarctica. Sport, Exercise, and Performance Psychology, 3, 237-287. DOI: $10.1037 /$ spy0000022

Watson D, Clark L. A, \& Tellegen A. (1988). Development and Validation of Brief Measures of Positive and Negative Affect: The PANAS scales. Journal of Personality and Social Psychology, 37, 395-412. http://dx.doi.org/10.1037/0022-3514.54.6.1063

Wood J, Schmidt L, Lugg D, Ayton J, Phillips T, Shepanek M. (2005). Life, survival, and behavioral health in small closed communities: 10 years of studying isolated Antarctic groups. Aviation, Space, and Environmental Medicine, 76, B89-93. 
MONITORING EVENTS, COPING STRATEGIES, AND EMOTION

Baseline scores for coping strategies, affect and mood

\begin{tabular}{|c|c|c|c|c|c|c|c|c|c|c|c|c|c|c|c|c|c|c|c|c|}
\hline \multirow[b]{2}{*}{ Participant } & \multicolumn{5}{|c|}{ Pre } & \multicolumn{6}{|c|}{ During } & \multicolumn{3}{|c|}{ Post (1-month) } & \multicolumn{6}{|c|}{ Follow (4-month) } \\
\hline & $M$ & $\mathbf{A}$ & B & $\mathrm{C}$ & $\mathbf{D}$ & $M$ & $\mathbf{A}$ & B & $\mathrm{C}$ & D & $M$ & $\mathbf{A}$ & B & $\mathrm{C}$ & D & $M$ & $\mathbf{A}$ & B & $\mathrm{C}$ & D \\
\hline $\begin{array}{l}\text { Active Problem } \\
\text { Solving }\end{array}$ & 3.21 & 3.00 & 3.14 & 3.29 & 3.42 & - & - & - & - & - & 2.96 & 2.71 & 3.29 & 2.71 & 3.14 & 3.39 & 3.14 & 4.00 & 2.71 & 3.71 \\
\hline $\begin{array}{l}\text { Palliative } \\
\text { Reaction }\end{array}$ & 2.06 & 2.00 & 2.38 & 2.25 & 1.63 & - & - & - & - & - & 1.97 & 2.00 & 1.75 & 2.00 & 2.13 & 1.88 & 1.75 & 2.00 & 2.00 & 1.75 \\
\hline Avoidance & 2.28 & 2.50 & 2.38 & 2.13 & 2.13 & - & - & - & - & - & 2.06 & 2.38 & 2.00 & 2.00 & 1.88 & 1.75 & 2.25 & 1.13 & 2.13 & 1.50 \\
\hline Social Support & 2.25 & 1.83 & 3.00 & 2.33 & 1.83 & - & - & - & - & - & 1.75 & 1.83 & 2.00 & 1.67 & 1.50 & 1.83 & 2.00 & 2.33 & 1.67 & 1.33 \\
\hline $\begin{array}{l}\text { Depressive } \\
\text { Reaction }\end{array}$ & 1.57 & 2.29 & 1.29 & 1.29 & 1.43 & - & - & - & - & - & 1.57 & 1.86 & 1.86 & 1.00 & 1.57 & 1.50 & 2.00 & 1.71 & 1.29 & 1.00 \\
\hline $\begin{array}{l}\text { Sharing } \\
\text { Emotions }\end{array}$ & 2.33 & 2.33 & 3.00 & 1.67 & 2.33 & - & - & - & - & - & 1.58 & 2.33 & 1.33 & 1.33 & 1.33 & 1.83 & 2.00 & 2.33 & 1.33 & 1.67 \\
\hline $\begin{array}{l}\text { Comforting } \\
\text { Cognitions }\end{array}$ & 2.85 & 2.20 & 2.40 & 3.00 & 3.80 & - & - & - & - & - & 2.30 & 2.40 & 1.80 & 2.60 & 2.40 & 2.55 & 2.20 & 2.80 & 2.80 & 2.40 \\
\hline Positive Affect & 3.80 & 3.90 & 3.80 & 4.40 & 3.10 & 3.56 & 4.33 & 1.91 & 4.06 & 3.46 & 3.80 & 4.40 & 2.10 & 4.10 & 4.60 & 4.43 & 3.50 & 4.80 & 4.50 & 4.90 \\
\hline Negative Affect & 1.93 & 3.30 & 1.40 & 1.90 & 1.10 & 1.11 & 1.15 & 1.17 & 1.07 & 1.08 & 1.18 & 1.30 & 1.20 & 1.10 & 1.10 & 1.45 & 1.30 & 2.20 & 1.10 & 1.20 \\
\hline Depression & 10.5 & 19.0 & 11.0 & 5.0 & 7.0 & - & - & - & - & - & 9.75 & 18.0 & 9.00 & 1.00 & 11.0 & 7.50 & 7.00 & 14.0 & 4.00 & 5.00 \\
\hline
\end{tabular}


Changes in events by expedition week

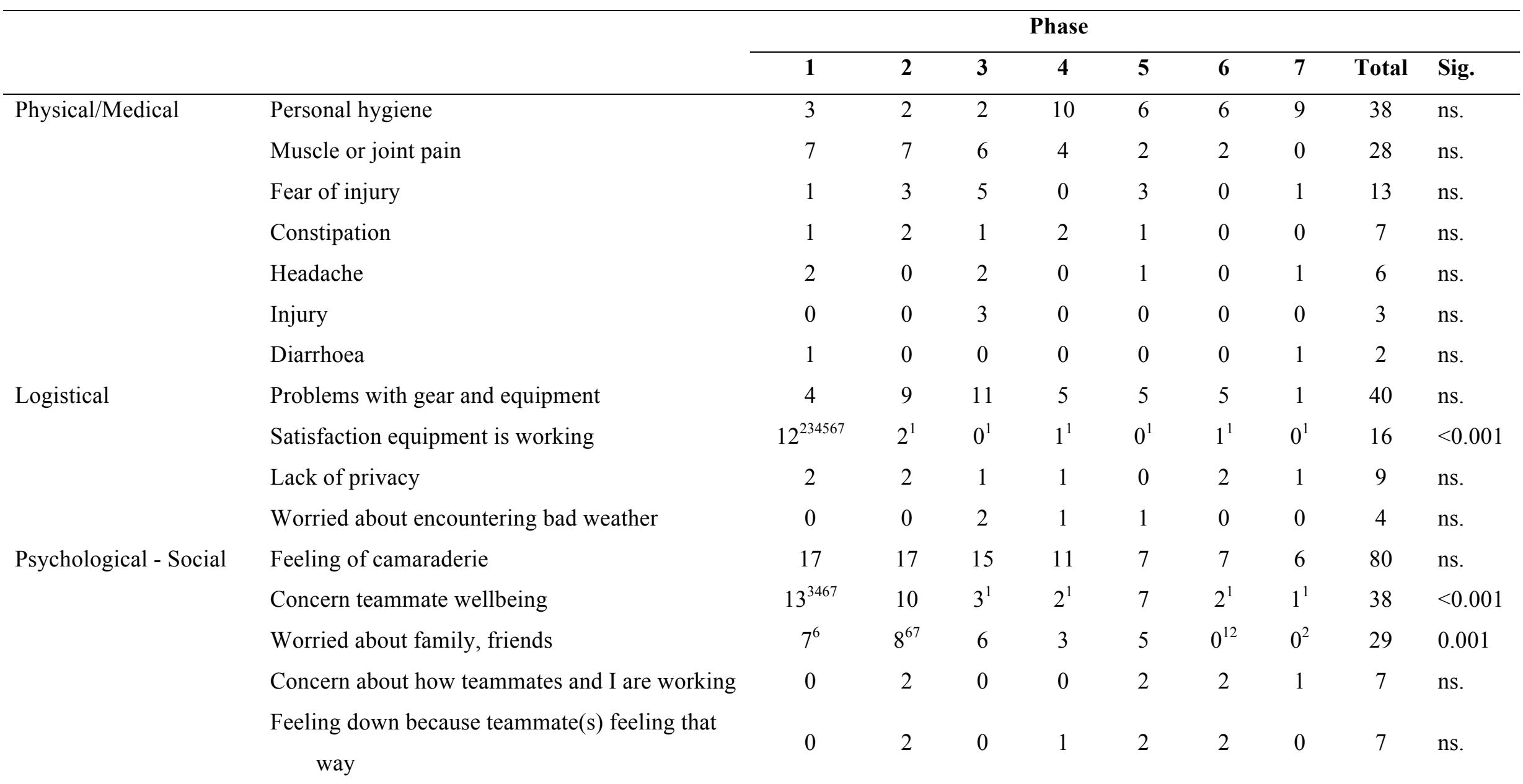


MONITORING EVENTS, COPING STRATEGIES, AND EMOTION

Tension with my teammate(s)

Psychological - $\quad$ Satisfaction in making good progress

Individual

\section{Enjoyed environment}

Satisfaction that I am able to cope

Loneliness

Concerns about safety of decisions I made today

$\begin{array}{ccccccccc}1 & 0 & 0 & 0 & 3 & 0 & 1 & 5 & \text { ns. } \\ 19 & 14 & 15 & 16 & 13 & 13 & 14 & 104 & \text { ns. } \\ 19^{5} & 18^{5} & 20^{5} & 16^{5} & 4^{1234} & 10 & 12 & 99 & <0.001 \\ 16 & 10 & 9 & 11 & 8 & 9 & 12 & 75 & \text { ns. } \\ 1 & 2 & 3 & 1 & 0 & 0 & 0 & 7 & \text { ns. } \\ 0 & 1 & 0 & 0 & 0 & 0 & 0 & 1 & \text { ns. }\end{array}$

Note: ${ }^{*} \mathrm{p}<.05 ; * * \mathrm{p}<.01 ; \mathrm{ns} .=$ non-significant. Superscript number $1-7$ indicates significant difference to the respective week. A Bonferroni corrected $\mathrm{p}$ value

580 of .002 is used to determine significance 
MONITORING EVENTS, COPING STRATEGIES, AND EMOTION

Table 3

Changes in coping strategies by expedition week

\begin{tabular}{|c|c|c|c|c|c|c|c|c|c|c|}
\hline & & \multicolumn{7}{|c|}{ Phase } & \multirow[b]{2}{*}{ Total } & \multirow[b]{2}{*}{ Sig. } \\
\hline & & 1 & 2 & 3 & 4 & 5 & 6 & 7 & & \\
\hline \multirow[t]{4}{*}{ Active approaches } & Broke task down, took it one day at a time & 12 & 10 & 11 & 11 & 10 & 9 & 7 & 70 & ns. \\
\hline & Engaged in effortful behaviour/Tried harder & 5 & 3 & 2 & 1 & 1 & 3 & 4 & 19 & ns. \\
\hline & Tried to solve situation & 0 & 4 & 1 & 2 & 2 & 0 & 0 & 9 & ns. \\
\hline & Yelled, stomped & 0 & 0 & 0 & 0 & 0 & 0 & 0 & 0 & ns. \\
\hline \multirow[t]{4}{*}{ Emotion-focused approaches } & Tried to think of something pleasant & 12 & $11^{7}$ & $9^{67}$ & 13 & 13 & $19^{3}$ & $19^{23}$ & 96 & 0.002 \\
\hline & Kept the goal in sight & 8 & 9 & 5 & 11 & 11 & 10 & 11 & 65 & ns. \\
\hline & Kept a positive attitude & 12 & 8 & 7 & 7 & 6 & 9 & 8 & 57 & ns. \\
\hline & Had negative feelings about myself & 0 & 1 & 0 & 0 & 0 & 0 & 0 & 1 & ns. \\
\hline \multirow[t]{2}{*}{ Social approaches } & Discussed task concerns & $1^{2}$ & $8^{14567}$ & 4 & $1^{2}$ & $1^{2}$ & $0^{2}$ & $1^{2}$ & 16 & 0.002 \\
\hline & Discussed personal/emotional concerns & 0 & 2 & 1 & 3 & 2 & 2 & 2 & 12 & ns. \\
\hline
\end{tabular}


MONITORING EVENTS, COPING STRATEGIES, AND EMOTION

Note: ${ }^{*} \mathrm{p}<.05 ;{ }^{*} \mathrm{p}<.01 ; \mathrm{ns} .=$ non-significant. Superscript number $1-7$ indicates significant difference to the respective week. A Bonferroni corrected $\mathrm{p}$ value

594 of .002 is used to determine significance 
Table 4

MLM model predicting daily positive and negative affect using events experienced

\begin{tabular}{|c|c|c|c|c|c|}
\hline & & \multicolumn{2}{|c|}{ Daily Positive Affect } & \multicolumn{2}{|c|}{ Daily Negative Affect } \\
\hline & & Estimate & Sig. & Estimate & Sig. \\
\hline \multirow[t]{7}{*}{ Physical/Medical } & Personal hygiene & .07 & .53 & -.06 & .12 \\
\hline & Muscle or joint pain & $-.32 *$ & .03 & .01 & .79 \\
\hline & Fear of injury & .16 & .40 & $.13^{*}$ & .03 \\
\hline & Constipation & .14 & .55 & -.09 & .22 \\
\hline & Headache & .36 & .15 & .00 & .79 \\
\hline & Injury & .43 & .24 & -.20 & .09 \\
\hline & Diarrhoea & .29 & .46 & -.06 & .66 \\
\hline \multirow[t]{5}{*}{ Logistical } & Role code $(0=$ support; $1=$ lead group $)$ & .59 & .61 & -.03 & .66 \\
\hline & Problems with gear and equipment & .07 & .54 & $.10^{*}$ & .01 \\
\hline & Satisfaction equipment is working & .12 & .47 & .03 & .50 \\
\hline & Lack of privacy & -.11 & .59 & .01 & .88 \\
\hline & Worried about encountering bad weather & .21 & .49 & -.13 & .16 \\
\hline \multirow[t]{5}{*}{ Psychological - Social } & Feeling of camaraderie & .16 & .15 & -.02 & .55 \\
\hline & Concern teammate wellbeing & -.03 & .77 & .06 & .12 \\
\hline & Worried about family, friends & .12 & .49 & $.12 *$ & .04 \\
\hline & Concern about how teammates and I are working & -.07 & .76 & $.23^{* *}$ & .00 \\
\hline & Feeling down because teammate(s) feeling that & .22 & .37 & .01 & .90 \\
\hline
\end{tabular}


MONITORING EVENTS, COPING STRATEGIES, AND EMOTION

way

Tension with my teammate(s)

$-.13$

.65

$-.02$

.81

Psychological - Individual

Satisfaction in making good progress

$.35 * *$

.00

$-.03$

.29

Enjoyed environment

$.17 \quad .10$

$-.01$

.71

Satisfaction that I am able to cope

$.21 *$

$-.05$

.17

Loneliness

.02

.05

$-.05$

.52

Concerns about safety of decisions I made today

$-.45 \quad .45$

$.61 * *$

.00

Note: ${ }^{*} \mathrm{p}<0.05 ; * * \mathrm{p}<0.01$ 
MONITORING EVENTS, COPING STRATEGIES, AND EMOTION

Table 5

MLM model predicting daily positive and negative affect using coping strategies

\begin{tabular}{|c|c|c|c|c|c|}
\hline & & \multicolumn{2}{|c|}{ Daily Positive Affect } & \multicolumn{2}{|c|}{ Daily Negative Affect } \\
\hline & & Estimate & Sig. & Estimate & Sig. \\
\hline \multirow[t]{4}{*}{ Active approaches } & Broke task down, took it one day at a time & -.10 & .42 & -.00 & .99 \\
\hline & Relaxed/meditated & $.07 *$ & .65 & -.03 & .52 \\
\hline & Engaged in effortful behaviour/Tried harder & -.01 & .95 & -.01 & .91 \\
\hline & Tried to solve situation & .11 & .64 & .11 & .14 \\
\hline \multirow[t]{7}{*}{ Emotion-focused approaches } & Tried to think of something pleasant & $.26^{*}$ & .02 & $-.06^{*}$ & .05 \\
\hline & Kept the goal in sight & .08 & .45 & $-.06^{*}$ & .05 \\
\hline & Kept a positive attitude & -.04 & .74 & .04 & .24 \\
\hline & Kept feelings to myself & -.11 & .31 & $.08 *$ & .04 \\
\hline & Tried to see the situation in a positive way & $.31^{*}$ & .01 & -.04 & .23 \\
\hline & Had negative feelings about teammate(s) & $-.71 *$ & .04 & $.26^{*}$ & .02 \\
\hline & Had negative feelings about myself & -.59 & .34 & .26 & .19 \\
\hline \multirow[t]{2}{*}{ Social approaches } & Discussed task concerns & .02 & .92 & $.11^{*}$ & .03 \\
\hline & Discussed personal/emotional concerns & $-.49 *$ & .01 & $.21 * *$ & .00 \\
\hline
\end{tabular}

Note: $* \mathrm{p}<.05 ; * * \mathrm{p}<.01$ 